\title{
CRESCIMENTO E REPRODUÇÃO DE HYALE MEDIA DANA (AMPHIPODA, GAMMARIDAE, HYALIDAE) ASSOCIADA À SARGASSUM CYMOSUM C. AGARDH
}

\author{
Fosca Pedini Pereira Leite ${ }^{1}$
}

\begin{abstract}
Growth and Reproduction of Hyale media Dana (Amphipoda, Gammaridae, Hyalidae) associated to SARgissum cymosum C. AgArdh. The postmarsupial growth, sexual differentiation, fecundity and reproductive biology of Hyale media Dana, 1853 living on Sargassum cymosum C. Agardh, 1820 are described. The growth was continuous througth 12 stages for males and 9 for females. The sexual differentiation occours at $2^{\text {th }}$ or $3^{\text {th }}$ moult and was demonstrated by the enlargment of the gnatopod II propod. Number of eggs increased with the female head length. Observations of courtship behavior, incubation, moult processes, emergence of juveniles and brood caracteristics were made. The precopula courtship continued for two days, the eggs were incubated for six days and the juveniles, that stay until three days in the marsupium, moult every day.

KEY WORDS. Amphipods, reproduction, growth, fecundity, Sargassum
\end{abstract}

Os Amphipoda são crustáceos bem sucedidos, tanto em número de indivíduos como de espécies, e parte deste sucesso pode ser atribuído à proteção à prole (BOROWSKY 1980). Nas últimas décadas foram apresentadas várias revisões dos estudos sobre o ciclo de vida e reprodução dos gamarídeos (MORINO 1978; NELSON 1980; VAN DOLAH \& BIRD 1980; WILDISH 1982; SAINTE-MARIE 1991), destacando-Se os de KRISHNAN \& JOHN (1974), BOROWSKY $(1983,1984,1986)$, BOROWSKY \& BOROWSKY (1987) e SHILLAKER \& MOORE (1987) sobre o comportamento reprodutivo e desenvolvimento dos ovos, e os de CroKER (1968), SHEADER \& CHIA (1970) e BOROWSKY (1980), sobre aspectos da eclosão dos ovos e desenvolvimento do marsúpio

O ciclo de vida de algumas espécies de Hyalidae foram estudados por MoORE (1976, 1986), MCBANE \& CroKer (1984), Hiwatari \& KAJHARA (1984), mas somente LEITE (1976) estudou Hyale media Dana,1853. Esta espécie é frequente e abundante em algas na região entre-marés (LEITE 1976; TARARAM \& WAKABARA 1981; TARARAM et al. 1986), associada ao bisso de Perna perna (JACOBI 1987), e no conteúdo estomacal de peixes de poças de maré (TARARAM \& WAKABARA 1982). LEITE \& WAKABARA (1989) estudaram aspectos do desenvolvimento embrionário e pós-embrionário de H. media enquanto LEITE et al. (1986) descreveram os oostégitos desta espécie e de outros gamarídeos.

Este trabalho visa complementar as informações existentes sobre Hyale media quanto ao seu crescimento e comportamento reprodutivo.

1) Departamento de Zoologia, Instituto de Biologia, Universidade Estadual de Campinas. Caixa Postal 6109, 13083-970, Campinas, São Paulo, Brasil. 


\section{MATERIAL E MÉTODOS}

\section{Crescimento, diferenciação sexual e fecundidade}

Os indivíduos de Hyale media foram separados de amostras mensais da alga Sargassum cymosum da Praia do Lamberto, Ubatuba ( $23^{\circ} 30^{\prime}$ 'S e $\left.45^{\circ} 07^{\prime} \mathrm{W}\right)$. Machos, fêmeas e jovens (indivíduos com sexo indiferenciado) foram contados e as fêmeas classificadas em três estágios: a) pré-ovígeras (portadoras de oostégitos em desenvolvimento na face interna da coxa do gnatópodo II e pereópodos I, II e III); b) ovígeras (com ovos e embriões no marsúpio); c) pós-ovígeras ou esvaziadas (com marsúpio vazio e oostégitos flácidos).

Mediu-se o comprimento de cabeça e o comprimento total, ou seja, da extremidade anterior da cabeça até a extremidade distal do telson de 253 indivíduos, projetando-se as medidas e escala milimetrada através da câmara clara de um microscópio estereoscópico Wild-5 para posterior análise de correlação entre as 2 variáveis. Obteve-se uma correlação linear entre os comprimento da cabeça (Lc) e

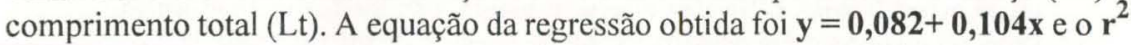
$=\mathbf{0 , 6 0 5}$. Em virtude de haver uma relação positiva entre os dois comprimentos utilizou-se o da cabeça para as análises de crescimento.

A diferenciação sexual foi estimada através da variação das medidas da cabeça e do comprimento e largura dos gnatópodos I e II de pelo menos 30 indivíduos de cada estádio morfológico (LeITE \& WAKABARA 1989). Para os estudos de fecundidade, foram contados e medidos os ovos no Estádio A (LEITE \& WAKABARA 1989) de pelo menos 30 fêmeas, quando possível.

\section{Comportamento reprodutivo}

Os animais, juntamente com as algas, foram coletados na Praia do Poço, Itanhaém, litoral sul do estado de São Paulo ( $24^{\circ} 12^{\prime} \mathrm{S}$ e $\left.46^{\circ} 47^{\prime} \mathrm{W}\right)$. Os animais a serem utilizados nas observações foram mantidos por até quatro meses em aquários de cinco litros de capacidade com água de origem, colocados em local não exposto à luz solar direta e com fotoperiodismo natural.

Os animais retirados do aquário para as observações eram colocados em placas de Petri de $10 \mathrm{~cm}$ de diâmetro, mantidas à temperatura ambiente, com parte da água trocada diariamente. Nestas placas eram colocados folíolos de Sargassum cymosum previamente escolhidos no microscópio estereoscópico, para servirem de alimento e abrigo aos animais.

Após saírem do marsúpio, os jovens eram colocados em placas de Petri de menor diâmetro para observações sobre tempo de muda. As exúvias ou mudas dos animais eram removidas assim que eram percebidas.

\section{RESULTADOS E DISCUSSÃO}

\section{Crescimento, diferenciação sexual e fecundidade}

Podem ser encontrados indivíduos jovens de Hyale media em até quatro estádios de crescimento, fêmeas em até nove e machos em até 12 estádios, sendo que os dois e três últimos estádios de jovens, fêmeas e de machos são de freqüência irregular e difíceis de serem encontrados na população. 
O número diferente de estádios de machos e de fêmeas sugere duas possibilidades: ou os períodos de intermudas teriam duração diferente ou os machos teriam ciclos de vida mais longos. A última hipótese parece ser a mais viável pois, devido ao maior número de fêmeas na população e razão sexual favorável (LEITE 1976), seria necessário que o macho tivesse um ciclo de vida mais longo para fecundar um maior número de fềmeas.

O tempo de duração de cada estádio é diferente entre jovens e adultos, ressaltando-se que varia entre os sexos. As fêmeas antes da maturidade, crescem mais rapidamente que os machos, após o que ambos têm sua taxa de crescimento diminuída (CHARNIAUX-COTTON 1957; KANNEWORFF 1965). Após a maturação há um aumento de tempo entre as mudas (CHARNIAUX-COTTON 1957; MYERS 1971).

A partir do estádio 5 o comprimento médio da cabeça das fêmeas se torna maior que o dos machos, mas este último atinge comprimentos médios maiores (Fig. 1). Deve-se considerar, contudo, um aumento das variações das médias (Tab. I). A partir do estádio 4 ocorre também, um grande alargamento do própodo, caracterizando portanto, o início da diferenciação morfológica dos machos (Fig. 2). Os indivíduos do estádio 4, ainda indiferenciados sexualmente, tem uma largura média superior à das fềmeas no mesmo estádio. Os comprimentos médios não mostram uma separação de tamanhos para macho e fêmea tão nítida como as larguras médias mas pode-se notar a ocorrência de 2 grupos de comprimentos médios (Fig. 3).

\begin{tabular}{|c|c|c|c|}
\hline Estádio & Jovem & Fêmea & Macho \\
\hline 1 & $0,21 \pm 0,034$ & & \\
\hline 2 & $0,26 \pm 0,037$ & & \\
\hline 3 & $0,33 \pm 0,024$ & $0,33 \pm 0,024$ & \\
\hline 4 & & $0,36 \pm 0,080$ & $0,38 \pm 0,088$ \\
\hline 5 & & $0,41 \pm 0,058$ & $0,39 \pm 0,062$ \\
\hline 6 & & $0,45 \pm 0,079$ & $0,43 \pm 0,078$ \\
\hline 7 & & $0,50 \pm 0,085$ & $0,47 \pm 0,087$ \\
\hline 8 & & & $0,51 \pm 0,097$ \\
\hline 9 & & & $0,54 \pm 0,088$ \\
\hline 10 & & & $0,58 \pm 0,110$ \\
\hline 11 & & & $0,60 \pm 0,154$ \\
\hline 12 & & & $0,63 \pm 0,120$ \\
\hline
\end{tabular}

O crescimento e alargamento do gnatópodo II, característica sexual secundária, de Hyale media é uma manifestação morfológica do sexo. Na fềmea este apêndice mantém, durante todo o desenvolvimento, uma forma juvenil, diferindo apenas no tamanho e na ornamentação (LEITE \& WAKABARA 1989).

A diferenciação do sexo em Hyale media ocorre na terceira muda ou em alguns indivíduos, já na segunda (estádios 4 e 3 respectivamente) e pode ser 
detectada externamente. Nestes estádios os machos adquirem o pênis, iniciam a modificação do gnatópodo II e surgem os oostégitos nas fêmeas. Estes são inicialmente reduzidos e após mais dois estádios tornam-se munidos de cerdas, indicando que a fêmea está apta para a reprodução (Figs 4-7). As alterações morfológicas, após a muda da diferenciação externa do sexo, também foram descritas por CHARNIAUXCOTTON (1957) em Orchestia gammarella (Pallas).

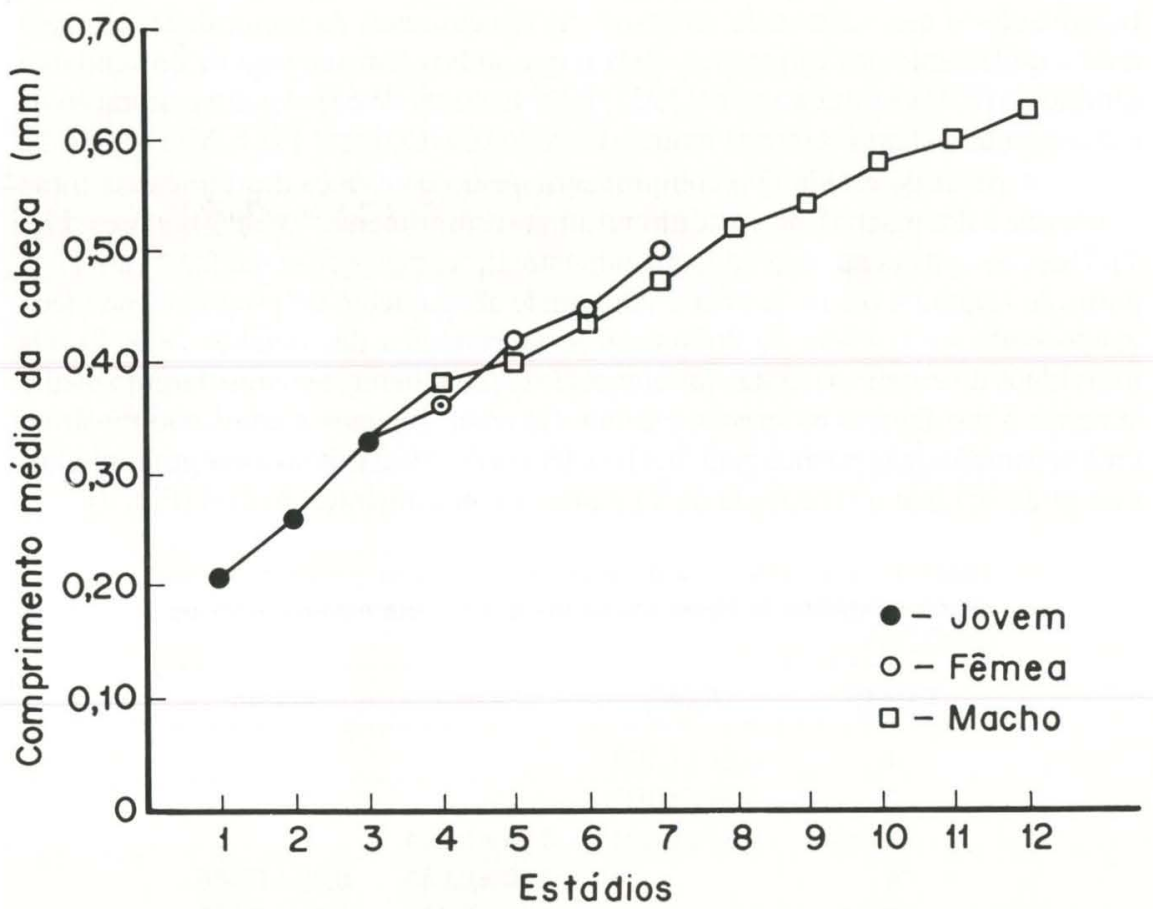

Fig. 1. Hyale media. Comprimento médio da cabeça $(\mathrm{mm})$ dos estádios de crescimento de jovens, fêmeas e machos ( $n=30$ em cada estádio).

As fêmeas de Hyale media, por ocasião da précopula, apresentam oostégitos munidos de longas cerdas com ganchos nas pontas, assegurando um bom fechamento das lamelas, evitando assim a perda de ovos. A fềmea não apresenta oostégitos quando não está em período reprodutivo. Este processo de crescimento e desenvolvimento dos oostégitos também foi observado por WATKIN (1941) e DEXTER (1972). O número médio de ovos aumenta com o comprimento da fêmea e depende do alimento, da temperatura e do tamanho e estádio de desenvolvimento da fêmea (SHEADER \& CHIA 1970). Pode haver diminuição do número de ovos com o fïm do período reprodutivo (HYNES 1954, 1955). As fêmeas de Hyale media apresentaram aumento do número médio de ovos, sem diminuição da fecundidade, com o aumento do tamanho (Fig. 8). 


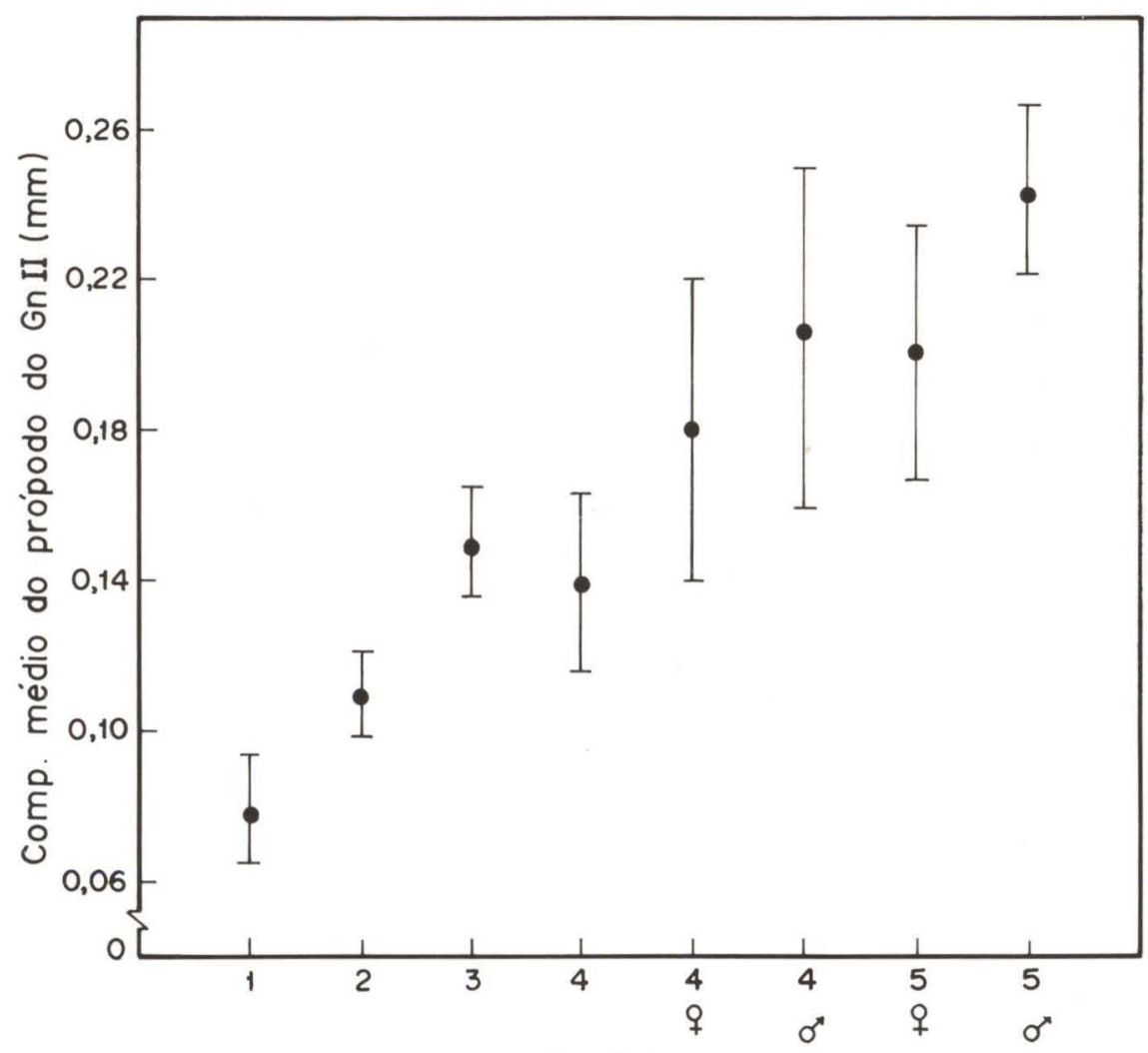

\section{Estódios}

Fig. 2. Hyale media. Comprimento médio $(\mathrm{mm})$ do própodo do gnatópodo II (Gnll) e desvio padrão nos estádios de crescimento ( $n=30$ em cada estádio).

O grande número de jovens de Hyale media presente no período estudado (LEITE 1976), sugere que o ambiente é favorável à espécie, proporcionando grande sobrevivência de jovens. Este dado é corroborado pelo pequeno número de ovos encontrados em cada fêmea, indicando pequena mortalidade pós-marsupial.

\section{Comportamento reprodutivo}

Ao iniciar o processo reprodutivo, o macho fica sobre a fêmea segurando-a firmemente com os gnatópodos, principalmente com o primeiro $(\mathrm{GnI})$, na região anterior do primeiro tergito torácico, auxiliado pelos dátilos dos pereópodos. Nesta posição, isto é, amplexo, nadam ativamente ao redor da placa de Petri, abrigando-se frequentemente sob os folíolos de Sargassum cymosum, sempre batendo os pleópodos ativamente. O macho é sempre maior que a fêmea e apresenta dimorfismo sexual com relacão ao gnatópodo II (Gn II). Nestas ocasiões a fêmea pode estar com marsúpio vazio ou portando ovos ou jovens. 


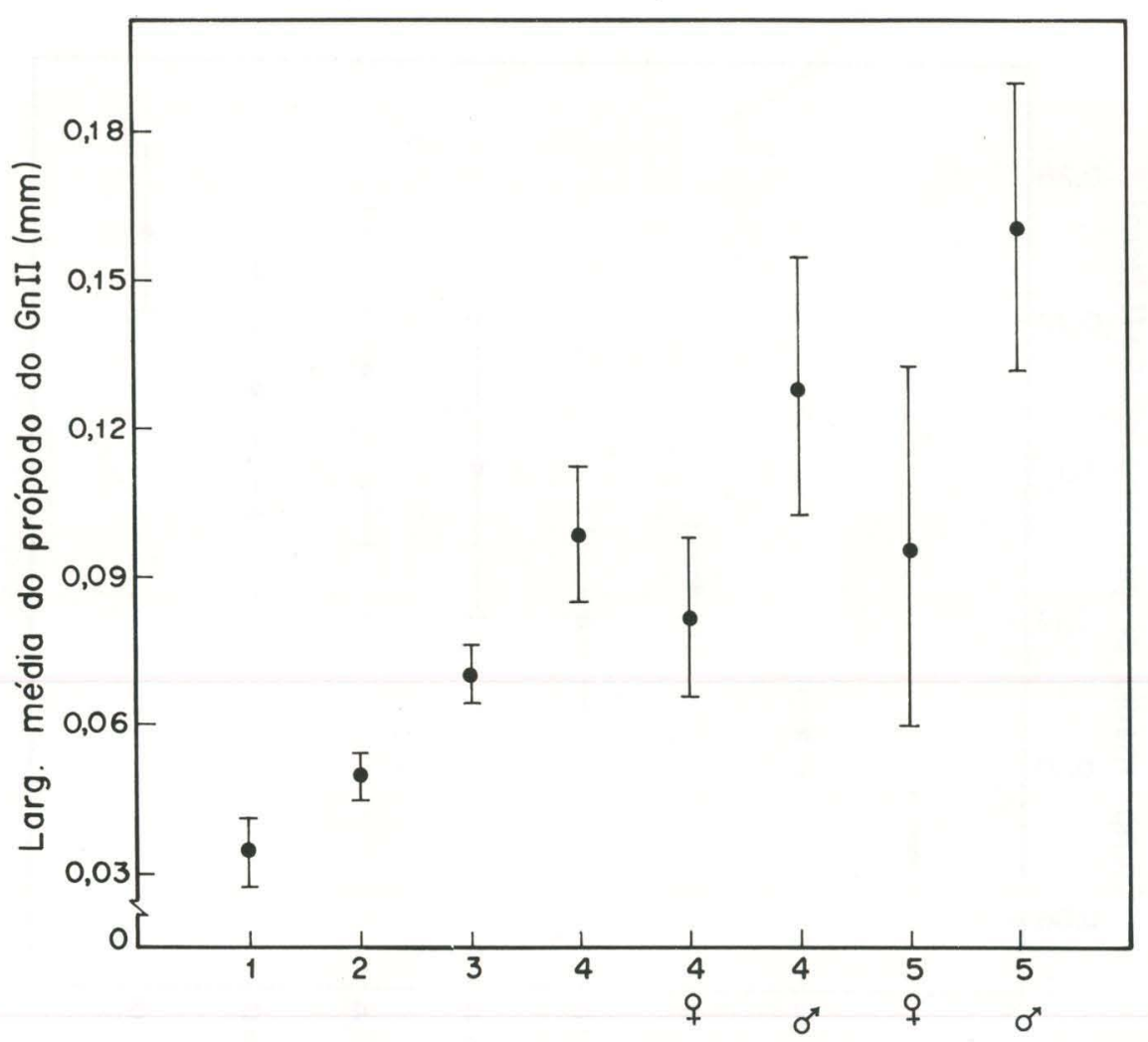

Estaidios

Fig. 3. Hyale media. Largura média $(\mathrm{mm})$ do própodo do gnatópodo II (GnII) e desvio padrão nos estádios de crescimento ( $\mathrm{n}=30$ em cada estádio).

O processo de acasalamento foi observado na íntegra por duas vezes e constou de muda da fêmea, da cópula e da liberação dos ovos no marsúpio. No primeiro caso transcorreu uma hora entre muda e fecundação da fêmea e mais 36 minutos até a liberação dos ovos no marsúpio; no segundo caso foram utilizados apenas 15 minutos entre a muda e a liberação dos ovos. Transcorreram dois dias desde o início da pré cópula até o aparecimento dos ovos no marsúpio (13 observações) constatando-se sempre a presença de ecdise da fêmea e algumas vezes do macho.

O período de incubação oscilou entre quatro e oito dias, sendo que a maioria das fêmeas incubou os ovos por seis dias (nove observações). Os jovens de Hyale media não saem imediatamente do marsúpio após romperem a membrana embrionária, ficando no seu interior por dois a três dias. No primeiro dia a maioria permanece dentro do marsúpio e nos outros dias, os jovens ficam, gradativamente, a maior parte do tempo fora. Permanecem ativos no interior do marsúpio, notando-se 
o movimento das antenas e batimentos dos pleópodos. Não foi observado retorno para o interior após a saída do marsúpio. Muitas vezes havia ocorrência de muda da fềmea e a exúvia era liberada com os jovens ainda dentro do marsúpio. KRISHNAN \& JOHN (1974) também descreveram alguns destes processos aqui relatados.

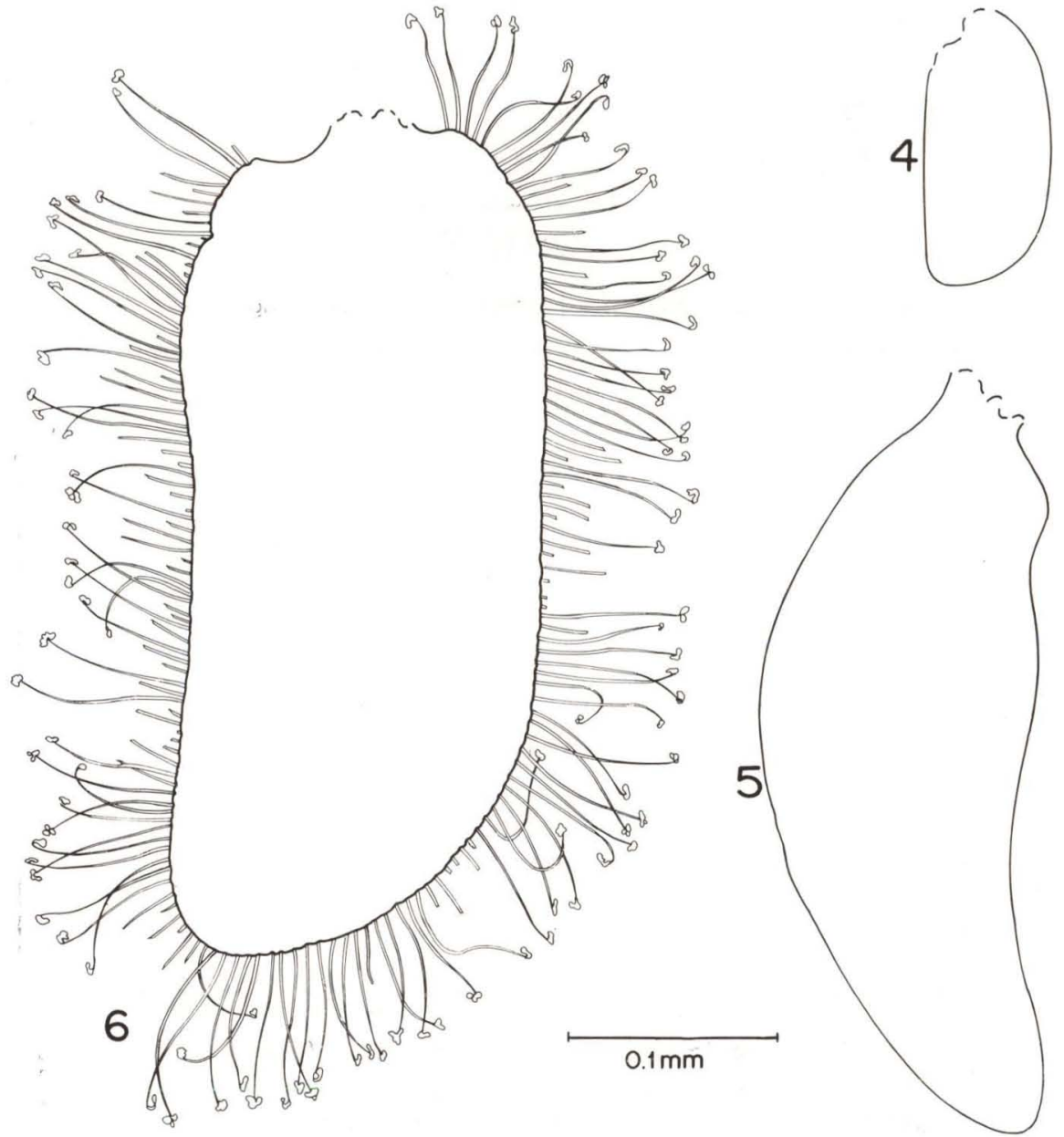

Figs 4-6. Hyale media. (4-5) Oostégitos de fêmeas imaturas (fases de crescimento); (6) Oostégitos de fêmeas ovigeras.

Nos jovens, o intervalo entre as mudas variava entre um a dois dias com predominância de um dia enquanto que, após a maturidade, o tempo aumentava oscilando entre dois a seis dias. Na maioria das observações ocorreram mudas alternadas de machos e fêmeas, às vezes simultâneamente.

Estes aspectos da biologia reprodutiva de Hyale media são muito semelhantes aos de Hyale pugettensis Dana, 1853 descritos por Low (1965). 


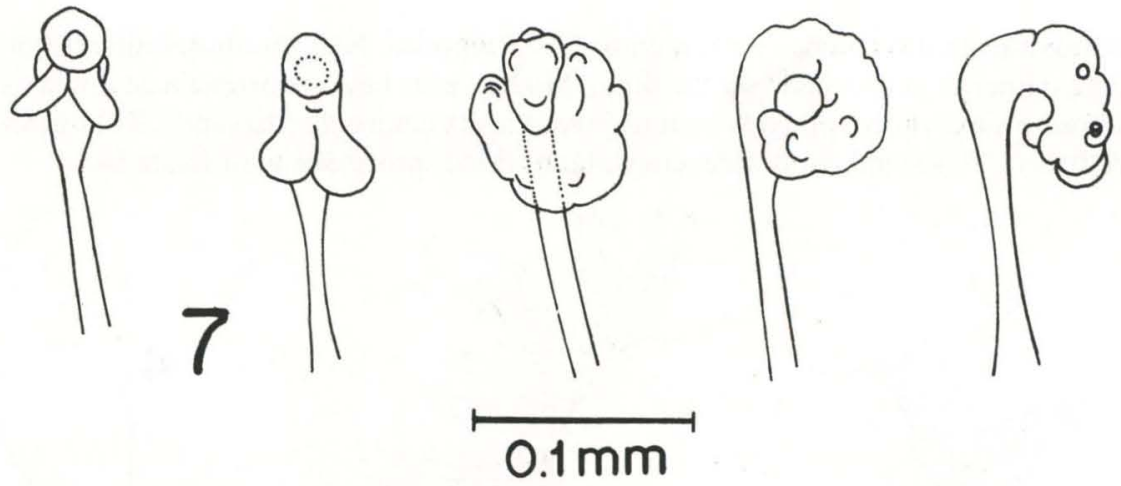

Fig. 7. Hyale media. Detalhes das cerdas de oostégitos de fêmeas ovigeras.

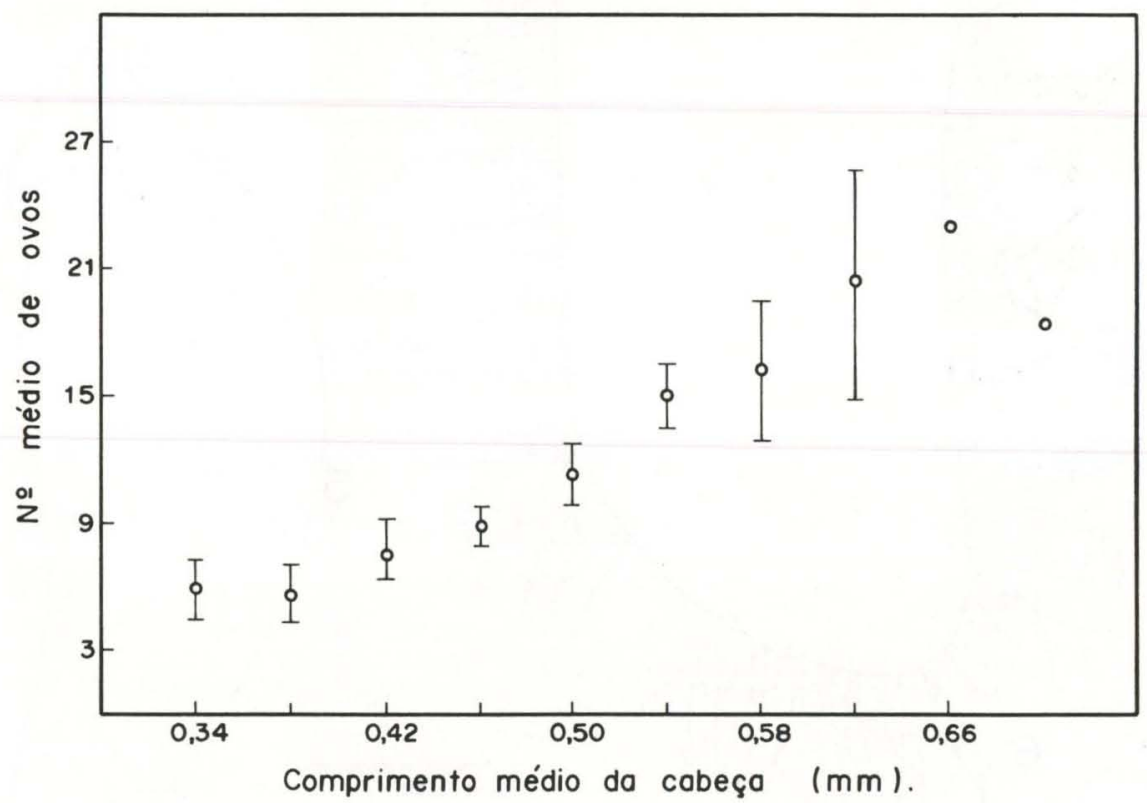

Fig. 8. Hyale media. Número médio de ovos e desvio padrão em relação ao comprimento médio da cabeça $(\mathrm{mm})$ das fêmeas ovigeras ( $\mathrm{n}=30$ em cada estádio).

AGRADECIMENTOS. À Dra. Yoko Wakabara; à Fundação de Amparo à Pesquisa do Estado de São Paulo (FAPESP, Proc. $n^{\circ} 71 / 1360$ ) e ao Conselho Nacional de Desenvolvimento Científico e Tecnológico (CNPq, Proc. $n^{\circ}$ 300337/82-5-OC).

\section{REFERÊNCIAS BIBLIGRÁFICAS}

BOROWSKY, B. 1980. Factors that affect juvenile emergence in Gammarus palustris (Bousfield, 1969). J. exp. mar. Biol. Ecol. 42 (3): 213-223. 
1983. Reproductive behavior of three tube building peracarid crustaceans: the amphipods Jassa falcata and Ampithoe valida and the tanaid Tanais cavolinii. Mar. Biol. 77: 257-263.

. 1984. The use of the males gnathopods during precopulation in some gammaridean amphipods. Crustaceana 3: 245-250.

. 1986. Laboratory observations of the pattern of reproduction of Elasmopus levis(Crustacea:Amphipoda). Mar. Behav. Physiol. 12: 245-256.

BorowsKY, B. \& R. BOROWSKY. 1987. The reproductive behaviors of the amphipod crustacean Gammarus palustris (Bousfield) and some insigths into the nature of their stimuli. J. exp. mar. Biol. Ecol. 107: 131-144.

CHARNiauX-CotTON, H. 1957. Croissance, régénération et determinisme endocrien des caráctères sexuels d'Orchestia gammarella (Pallas). Crustacé amphipode. Annls. Sci. nat.19 (4): 411-560.

CROKER, R.A. 1968. Return of juveniles to the marsupium in the amphipod Neohaustorius schmitzi Bousfield. Crustaceana 14: 215.

DEXTER, D.H. 1972. Comparison of the community structures in a Pacific and an Atlantic panamanian sandy beach. Bull. mar. Sci. 22 (2): 449-462.

HiwataRi, T \& T. KaJihara. 1984. Population dynamics and life cycle of Hyale barbicornis (Amphipoda, Crustacea) in a blue mussel zone. Mar. Ecol. Prog. Ser. 20: 177-183.

HYNES, H.B.N. 1954. The ecology of Gammarus duebeni Lilljeborg and its occourrence in fresh water in western Britain. J. Anim. Ecol. 23 (1): 38-84.

1955. The reproductive cycle of some British fresh water Gammaridae. J. Anim. Ecol. 24: 352-387.

JACOBI, C.M. 1987. Spatial and temporal distribution of Amphipoda associated with mussel beds from the Bay of Santos (Brazil). Mar. Ecol. Prog. Ser. 35: 51-58.

KANNEWORFF, E. 1965. Life cycle, food and growth of the amphipod Ampelisca macrocephala Liljeborg from the Oresund. Ophelia 2 (2): 305-318.

KRISHANAN, L. \& P.A. JOHN. 1974. Observations on the breeding biology of Melita zeylandica Stebbing a brackish water amphipod. Hydrobiologia 44 (4): 413-430.

LEITE, F.P.P. 1976. Estádios de crescimento e aspectos da reprodução de Hyale media (Crustacea, Amphipoda, Hyalidae) da fauna vágil de Sargassum cymosum. Dissertação de Mestrado, não publicada, Instituto Oceanográfico, Universidade de São Paulo, São Paulo, 74p.

LEITE, F.P.P. \& Y. WAKABARA. 1989. Aspects of marsupial and post marsupial development of Hyale media (Dana, 1853) (Hyalidae, Amphipoda). Bull. mar. Sci.45 (1): 85-97.

LeITE, F.P.P.; Y. WAKabara \& A.S. TARARAm. 1986. On the morphological variations in oostegites of gammaridean species (Amphipoda). Crustaceana 51 (1): 77-94.

Low, J. 1965. Preliminary studies on Hyale pugettensis (Dana), a tide pool amphipod. Student Report Zool. 533b (summer), Friday Harbor Laboratories Library, 34p. 
MCBANE, C.D. \& R.A. CROKER. 1984. Some observations on the life history of the amphipod crustacean Hyale nilssoni (Rathke), in New Hampshire. Estuaries 7 (4B): 541-545.

MOORE, P.G. 1976. Organization in simple communities: observations on the natural history of Hyale nilssoni (Amphipoda) in high littoral seaweeds, p.443-451. In: B.F. KeEgAN, B.F.; P.O. CEIdIGH \& P.J.S. BOAdEN (Ed.). Biology of benthic organisms. Oxford, Pergamon Press Oxford, 630p.

MoORE, P.G. 1986. Seaweed associated animal communities in the Firth of Clyde with special reference to the population biology of the amphipod Hyale nilssoni (Rathke). Proc. Royal Soc. Edinb. 90B: 271-286.

MORINO, H. 1978. Studies on the Talitridae (Amphipoda, Crustacea) in Japan. III. Life history and breeding activity of Orchestia platensis Kroyer. Publ. Seto mar. biol. Lab 24 (4-6): 245-267.

Myers, A. A. 1971. Breeding and growth in laboratory reared Microdeutopus gryllotalpa Costa. J. nat. Hist. 5: 271-277.

NELSON, W.G. 1980. Reproductive patterns of gammaiidean amphipods. Sarsia 65 (2): $61-71$.

SAINTE-MARIE, B. 1991. A rewiew of the reproductive bionomics of aquatic gammaridean amphipods: variation of life history traits with latitude, depth, salinity and superfamily. Hydrobiologia 223: 189-227.

SHEADER, M \& F.S. CHIA. 1970. Development, fecundity and breeding behaviour of the amphipod Marinogammarus obtusatus. J. mar. biol Ass. U.K. 50: 1079-1099.

SHILlAKER,R.O. \& P.G. MOORE. 1987. The biology of brooding in the amphipods Lembos websteri Bate and Corophium bonelli Milne Edwards. J. exp. mar. Biol. Ecol. 110 (2): 113-132.

TARARAM, A.S. \& Y. WAKABARA. 1981. The mobile fauna, specially Gammaridea, of Sargassum cymosum. Mar. Ecol. Prog. Ser. 5: 157-163.

TARARAM, A.S. \& Y. WAKABARA. 1982. Notes on the feeding of Blennius cristatus Linnaeus from a rocky pool of Itanhaém, São Paulo State. Bolm. Inst. oceanogr. 31 (2): 1-3.

TARARAM, A.S.; Y. WAKABARA \& F.P.P. LEITE. 1986. Vertical distribution of amphipod living on algae of a brazilian intertidal rocky shore. Crustaceana 51 (2): 183-187.

VAN DOLAH, R.F. \& E. BIRD. 1980. A comparison of reproductive patterns in epifaunal and infaunal gammaridean amphipods. Est. Coastal mar. Sci. 2: 583-604.

WATKIN, E.E. 1941. Observation on the nigth tidal migrant Crustacea of Kames Bay. J. mar. biol. Ass. U.K. 25: 81-96.

WILDISH, D.J. 1982. Evolutionary ecology of reprodution in gammaridean amphipoda. Int. Jour. Invert. Reprod. 5: 1-19.

Recebido em 01.II.1995; aceito em 07.XI.1996. 